\title{
A intervenção do serviço social no protelamento da alta do idoso no serviço de urgência: o caso do hospital de São José
}

\author{
The intervention of social work in the postponement of the elderly \\ discharge from the emergency service: the case of São José hospital
}

Janine Almeida ${ }^{1}$

Paula Ferreira ${ }^{2}$

\begin{abstract}
Resumo
O presente artigo visa analisar o processo de gestão do protelamento de alta dos doentes idosos, no serviço de urgência do Hospital de São José, efectuada pela equipa de serviço social. Foi realizada uma triangulação metodológica suportada na consulta e análise dos processos sociais, entrevistas à equipa multidisciplinar e análise documental. Os objetivos centraram-se na definição do perfil do utente, motivos de protelamento, destino pós-alta e dificuldades inerentes à atividade do serviço de urgência. Destaca-se como resultados os doentes do género feminino, com idade entre os 81-85 anos, tendo como motivos de protelamento decorrentes sobretudo de incapacidade/ indisponibilidade da rede de suporte informal e a insuficiência/ demora da resposta social formal. Por conseguinte, a gestão do protelamento de alta do idoso é efetuada pela equipa multidisciplinar, destacando-se neste contexto o papel mediador do assistente social neste processo.
\end{abstract}

Palavras-chave: idoso, urgência hospitalar, serviço social, protelamento de alta.

\begin{abstract}
This article aims to analyze the management process of postponement of discharge of elderly patients, in the emergency service of São José Hospital, carried out by the social service team. A methodological triangulation supported in the consultation and analysis of social processes, interviews with the multidisciplinary team and documentary analysis was carried out. The objectives were centered on the definition of the user's profile, reasons for postponement, post-discharge destination and difficulties inherent to the activity of the emergency service. Stands out as main results most patients are female, aged 81-85, with reasons for delaying mainly due to inability / unavailability of the informal support network and insufficiency / delay in the formal social response. The management of the discharge delay of the elderly is carried out by the multidisciplinary team, highlighting in this context the mediating role of the social worker in this process.
\end{abstract}

Keywords: elderly, hospital urgency, social work, postponement of discharge.

\footnotetext{
${ }^{1}$ Assistente Social no CHULC,Epe - Serviço de Urgência Polivalente do Hospital de São José | E-mail: janinealmeida5@gmail.com

${ }^{2}$ Professora Auxiliar na Universidade Lusófona de Humanidades e Tecnologias, Instituto de Serviço Social | E-mail: p5642@ulusofona.pt
} 


\section{Introdução $^{3}$}

A questão do envelhecimento populacional constitui, nos dias de hoje, uma preocupação central, não só a nível europeu, como a nível mundial. O impacto do envelhecimento revela-se nas diferentes esferas da vida social e económica, contudo é no campo da prestação de cuidados de saúde que este parece apresenta uma maior expressão.

Sabemos que o envelhecimento constitui um processo natural e dinâmico que ocorre ao longo de toda a vida do indivíduo (Lima, 2010), no entanto, a ele estão associadas diversas modificações morfológicas, funcionais, bioquímicas e psicológicas que conduzem a uma perda gradual das capacidades físicas do organismo humano, assim como a uma transformação dos processos cognitivos e sensoriais e, consequentemente, a uma maior vulnerabilidade e incidência de processos patológicos e de situações de dependência (Imaginário, 2008; Cancela, 2007; Sequeira, 2010).

Perante esta crescente necessidade ao nível dos cuidados pessoais, sociais e de saúde, e num quadro de diminuição de recursos familiares e financeiros, revela-se necessário investir em serviços de apoio, sendo a este nível que se coloca a intervenção do serviço social.

O serviço social na saúde, especificamente, em contexto hospitalar, tem vindo a desenvolver um percurso progressivo nas equipas multidisciplinares, tendo um papel fundamental na identificação de fatores que correlacionam a saúde/doença e todo o contexto em que o idoso se insere (Guerra, 2017; Espírito Santo, 2018). O desenvolvimento da intervenção pelo serviço social destaca-se na identificação e referenciação de situações de risco e problemas sociais, realizando o encaminhamento e orientação dos doentes e familiares. Assume, igualmente, a sua importância no desenvolvimento e interligação das relações existentes com instituição hospitalar, comunidade, recursos da comunidade, redes de vizinhança e família, entre outros, assumindo-se o assistente social como mediador e facilitador entre todos estes intervenientes (Pires, 2000).

\section{O serviço social no serviço de urgência}

Os hospitais sempre estiveram associados à doença aguda, contudo a actual evolução demográfica e as novas determinantes do paradigma epidemiológico (como a elevada prevalência das doenças crónicas, presença de múltiplas patologias, entre outras)

\footnotetext{
${ }^{3}$ Este artigo resulta da dissertação de mestrado em Gerontologia Social apresentada em maio de 2020 no ISS-ULHT, tendo, todavia, sofrido algumas alterações para este mesmo efeito.
} 
têm conduzido à necessidade de um maior ajustamento a estes novos desafios, garantindo uma resposta aos doentes, em tempo útil e ao mais baixo custo (Ministério da Saúde, 2010).

Dentro deste contexto, o serviço de urgência polivalente (SUP) distingue-se pelo facto de proporcionar cuidados de saúde a pessoas em situação de urgência/emergência, na decorrência de um episódio eminente, súbito e inesperado (Direção-Geral de Saúde, 2001).

Sendo diverso o perfil do utente que recorre a este tipo de serviço, sabe-se, que a afluência da população (sobretudo idosa) tem, nos últimos anos, registado um crescimento significativo, como resultado dos múltiplos problemas de saúde (Oliveira et al, 2017; Salvi et al, 2007). A título ilustrativo refira-se o estudo de Oliveira, Frutuoso, Veríssimo \& Agripino (2017), em que se verifica que 32,4\% das pessoas que recorrem ao SUP possuem mais de 65 anos, apresentando maior probabilidade de ficarem internados e com uma mediana de estadia mais longa, quando comparado com outros grupos etários. Destacam-se, assim, deste estudo duas conclusões importantes: o idoso apresenta maior tempo de permanência no SUP e uma taxa de internamento superior a um utente mais jovem.

Quanto à intervenção do serviço social em contexto de urgência, Masfret (2000) salienta a sua relevância no planeamento da alta hospitalar - desde a avaliação social (no serviço de urgência), ao acompanhamento do caso (aquando da sua passagem para o serviço de internamento), até à articulação com os serviços de comunidade (na preparação da alta). Bywaters \& Mcleod (2003) destacam ainda a sua capacidade para melhorar a eficiência e eficácia hospitalar, através de prevenção de readmissões, programação da alta hospitalar para o domicílio, redução dos protelamentos de alta por motivos sociais, mediação e melhoria da comunicação e informação entre os doentes e equipa multidisciplinar, possibilitando "economizar tempo" à equipa clínica.

Já Silva, Marinho \& Delfino (2016), referem o papel do serviço social na mediação de situações de abandono familiar (razão apontada pelos autores como a principal razão para o protelamento das altas dos idosos), concretizando princípios como: defesa dos direitos humanos contra todo o tipo de arbítrio e autoritarismo; defesa da equidade e da justiça social, universalizando o acesso a bens e serviços relativos a programas e políticas sociais e a sua gestão democrática; compromisso com a qualidade na prestação de serviços, competência profissional e articulação com outros profissionais. Ao mesmo tempo enunciam instrumentos técnico-operativos, como: 
Entrevistas, relatórios e encaminhamentos, capaz de potenciar as ações nos níveis de negociação, ação direta, estimuladora da participação dos pacientes nas decisões que lhes dizem respeito quando demonstrarem possibilidades, defesa de direitos e no acesso aos meios de exercê-los (p.23).

Sendo comuns estes princípios, assim como o tipo de instrumentos técnicooperativos que servem de suporte à intervenção do serviço social hospitalar, estes têm, todavia, que ter sempre em conta as especificidades de cada caso/doente. Como salienta Masfret (2012), "o plano de Serviço Social de saúde de uma pessoa diagnosticada com demência tipo Alzheimer, não pode ser o mesmo de uma pessoa diagnosticada com diabetes ou que tenha sofrido um acidente de trabalho com queimaduras graves" (p.64).

\section{Da alta clínica ao protelamento social no serviço de urgência}

A rentabilização dos recursos de saúde está cada vez mais presente em todas as áreas de intervenção direta com o utente, nomeadamente ao nível do planeamento da alta hospitalar (Lopes, Ribeiro, Santo, Ferreira \& Frederico, 2013). Como Ferreira \& Espírito Santo (2018) afirmam:

um plano efectivo de alta, diminui os custos para os serviços de saúde, prevenindo novos eventos hospitalares, promove a educação para a saúde na compreensão quanto a esquemas terapêuticos, e subsequentemente fomenta a satisfação dos doentes e suas famílias (p.4).

Segundo a Direção-Geral de Saúde (2004) o planeamento da alta hospitalar é entendido como "um processo complexo que exige uma efetiva comunicação entre os membros da equipa, o doente e a sua família, que deve considerar as necessidades de equipamentos materiais e sociais e a ligação com quem na comunidade providencia os cuidados e serviços necessários” (p.3), a sua planificação segundo Ferreira (2012) pode ser definida como:

um processo centralizado, coordenado e interdisciplinar, no qual os membros da equipa de saúde colaboram com os doentes e suas famílias, antecipando as necessidades destes depois da hospitalização, desenvolvendo um plano que os ajudará a ganhar independência e a manter os benefícios ganhados durante a estadia no hospital (p.34). 
Neste pressuposto, a avaliação da equipa multidisciplinar possibilita analisar o doente na sua unicidade e multidimensionalidade, devendo a decisão de alta hospitalar ser construída conjuntamente para garantir a resposta às necessidades do doente. Contudo, os constrangimentos na intervenção com a população idosa são diversos - com problemas sociais e de saúde, associados ao risco de pobreza, solidão, isolamento, necessidade de cuidados alargados e diferenciados, questões de discriminação pela idade, questões de violência, entre outros (Ferreira, 2012).

Neste contexto é fundamental, como referem Ferreira \& Espírito Santo (2018), que o assistente social possa "identificar precocemente os problemas sociais que podem impedir a alta do doente, definindo um plano de intervenção (...) de modo a garantir a inserção deste na comunidade com segurança e com continuidade de cuidados” (p.4).

O papel do assistente social assume, assim, primordial importância, sobretudo nos serviços que mais diretamente se relacionam com a prestação de cuidados de saúde aos idosos. Deste modo, e conforme Ferreira (2012) afirma:

o desempenho dos assistentes sociais desenvolve-se tanto ao nível do apoio psicossocial ao doente e família, como ao nível da articulação dos serviços, internos externos, assegurando a ligação à rede de suporte ao doente e família/ cuidador, onde se insere o planeamento da alta. (p.43)

Para além disso, e como Ferreira \& Espírito Santo (2018) realçam:

em algumas situações e em determinados casos que apresentam complexos problemas sociais, a alta clínica não supõe a saída do doente do hospital, ou seja, embora o doente não apresente condicionantes do foro clínico para permanecer no hospital, por vezes o contexto social do doente não reúne as condições necessárias/básicas para a sua reinserção na comunidade, e como tal, o doente permanece hospitalizado enquanto a sua situação social não é resolvida (p.3).

Este tipo de situação, constitui protelamento da alta hospitalar (mesmo com alta clínica, não estão reunidas as condições para a alta social). Nesta fase, segundo Jesus (2017) a intervenção do assistente social passa, sobretudo, por assumir "a função de mediador entre o utente, família, equipa terapêutica e comunidade promovendo a articulação entre as mesmas" (p. 79). 
O reconhecimento da importância dos protelamentos de alta hospitalar faz com que este se assuma como um objeto de investigação em diferentes áreas do conhecimento. Dos estudos realizados é possível definir o perfil de utente, bem como identificar as suas principais causas.

Trata-se sobretudo de utentes do sexo feminino, reformados, com idades entre os 80-89 anos, em situação económica precária, internados em serviço de medicina, com doença vascular e neurológica, com grande debilidade física e cognitiva e com cerca de 67 dias em protelamento de alta (Ramos, 2015; Jesus, 2017; Ferreira \& Espírito Santo, 2018; Associação Portuguesa de Administradores Hospitalares, 2018).

Quanto às causas de protelamento de alta, Ferreira \& Espírito Santo (2018) referem causas internas e externas ${ }^{4}$, relacionadas sobretudo com a escassez e incapacidade de recursos institucionais na comunidade, de forma a responder em tempo útil às necessidades dos doentes, verificando-se que os utentes permanecem em internamento, maioritariamente, a aguardar integração em estruturas residências para idosos, resposta de serviço de apoio domiciliário ou outro tipo de respostas.

Ao mesmo tempo, as situações familiares configuram-se como situações complexas, com relações conflituosas, de indisponibilidade, incapacidade física e psicológica para a prestação de cuidados (Jesus, 2017; Ferreira \& Espírito Santo, 2018; Associação Portuguesa de Administradores Hospitalares, 2018). Este contexto leva a maioria dos utentes em protelamento de alta hospitalar, acabem por ser institucionalizados (assumindo-se este como o principal destino pós-alta). De seguida surge o retorno ao domicílio - após ter sido garantida a resposta às necessidades, face à situação de saúde e dependência. Por último, surgem outros destinos, tais como, centros de acolhimento, quartos, instituições de acolhimento a grupos específicos e domicílio de familiares (Jesus, 2017; Ferreira \& Espírito Santo, 2018).

Adicionalmente, estudos apontam que os utentes com situações de menor complexidade são, sobretudo, utentes com apoio familiar e com um maior envolvimento familiar na intervenção social. Já as situações mais complexas estão associadas a situações de incapacidade de apoio familiar. Contudo, também é mencionado que existem situações com apoio familiar consideradas de complexidade alta, em que a família e/ou o utente colocam obstáculos de natureza diversa. Neste sentido, na análise entre o nível de

\footnotetext{
${ }^{4}$ Identificam como causas internas, aquelas que se associam ao funcionamento interno da instituição e seus profissionais. Como causas externas identificam os fatores externos ao utente e à instituição, mas que implicam segurança na continuidade de cuidados fora do hospital.
} 
complexidade e as causas de protelamento, verifica-se que os níveis mais altos de complexidade têm como principal causa de protelamento a integração institucional (Jesus, 2017).

Pese embora, a análise destas situações implique a intervenção de diferentes profissionais, a análise, avaliação e planeamento de altas dos “casos sociais" em contexto hospitalar estão adstritos à intervenção do serviço social, assumindo este uma importância significativa para a garantia da eficácia e eficiência do funcionamento dos serviços, assim como para a garantia de apoio e prevenção das disfunções com vista à integração social após alta hospitalar (Serafim \& Santo, 2013; Guerra, 2017).

\section{Metodologia}

O desenvolvimento de uma investigação visa, segundo Berger (1998), a descoberta de algo de novo sobre temáticas de interesse pessoal e global. Neste sentido, a investigação assume-se como um processo de análise de problemas ligados aos fenómenos reais e vividos pelas pessoas.

O objetivo da presente investigação passou por analisar a gestão do protelamento de alta dos doentes idosos, no SUP do Hospital de São José, tendo como principais preocupações: 1) caracterizar o perfil do idoso em protelamento de alta; 2) identificar dificuldades da equipa multidisciplinar na gestão do protelamento de alta do idoso; 3) identificar os motivos de protelamento de alta; 4) compreender o processo de planeamento de alta do doente idoso, em situação de protelamento, desenvolvido pela equipa multidisciplinar, com relevância para o papel do serviço social.

Para tal, selecionou-se o campo empírico - o SUP do Hospital de São José - Centro Hospitalar Universitário Lisboa Central, EPE - e definiu-se o universo: utentes com idade igual ou superior a 65 anos em situação de protelamento de alta por motivos sociais.

Face à impossibilidade de se proceder a uma análise exaustiva de todos os casos registados (quer por razões associadas ao tempo previsto para esta investigação, quer por dificuldade de acesso aos dados), optou-se por estabelecer um critério temporal, elegendo como período de referência o ano de 2018 , tendo sido o primeiro ano de registos efectivos de doentes em protelamento por motivos sociais. Definido este critério estabeleceu-se, então, como amostra: os utentes com idade igual ou superior a 65 anos em situação de protelamento, no ano de 2018.

Do ponto de vista das técnicas de recolha de dados, optou-se por uma triangulação metodológica suportadas na consulta e análise dos processos sociais, entrevistas à equipa 
multidisciplinar e análise documental. Com esta estratégia procurou-se não apenas reter características holísticas e significativas dos acontecimentos da vida real (Yin, 1994), como fornecer uma melhor compreensão sobre uma realidade ainda pouco estudada.

Numa primeira fase procedeu-se à análise dos processos sociais dos utentes, tendo sido para este efeito criado uma grelha composta por cinco categorias de análise e nesta sequência foi elaborada base de dados própria em excel:

A. Caracterização do utente (género, idade, estado civil, concelho e isenção de taxas moderadoras por insuficiência económica);

B. Condição clínica (causas de admissão no SUP, grau de dependênciapreviamente e após episódio de urgência, doenças diagnosticadas);

C. Redes de Suporte (tipo de rede de suporte, tipo de rede de suporte previamente ao episódio de urgência);

D. Plano de alta Serviço Social (acções desenvolvidas);

E. Protelamento de alta (datas - admissão, sinalização, alta clínica, alta social, número total de dias de protelamento, motivos de protelamento, resposta social pós-alta e destino pós-alta).

Após este primeiro momento da análise, e de forma a complementar os dados obtidos nos processos sociais, foram efectuadas entrevistas à equipa multidisciplinar do SUP. Nesta fase, optou-se pela seleção de uma amostra não-probabilística intencional, tendo os profissionais sido selecionados em função do seu perfil e posição ocupada na equipa. Assim, foram entrevistados sete elementos: um médico chefe de equipa de medicina interna; um médico membro da direção; um enfermeiro; um enfermeiro da direção; um assistente social; uma coordenadora da área de apoio social; uma administradora hospitalar.

Foram realizadas entrevistas semiestruturadas, organizado em três grandes categorias: A. Intervenção/funções do profissional, B. Funcionamento e articulação com equipa multidisciplinar, C. Gestão do protelamento de alta no SUP.

As respostas obtidas foram sujeitas a uma análise de conteúdo, por ser, como refere Vala (2007), "uma das técnicas mais comuns na investigação empírica realizada pelas diferentes ciências humanas e sociais" (p.101) e por permitir, como acrescenta Bardin (1995), “obter, por procedimentos, sistemáticos e objectivos de descrição do conteúdo das mensagens, indicadores (quantitativos ou não) que permitam inferência de conhecimento relativos às condições de produção/recepção (variáveis inferidas) destas mensagens" (p.42). 
Adicionalmente, foi ainda realizada uma análise de documentos internos institucionais relativos ao tema. Segundo Lessard-Hébert et al (1990), a análise documental é uma "espécie de análise de conteúdo que incide sobre documentos relativos a um local ou uma situação, corresponde, do ponto de vista técnico, a uma observação de artefactos escritos" (p.143). Neste contexto, foi fundamental o acesso às informações internas da instituição relativas ao planeamento e gestão da alta, tendo esta técnica sido transversal a todas as etapas da investigação, não apenas pela sua importância na aquisição de informação e conhecimento sobre o tema em estudo, mas também na conciliação e triangulação das diferentes técnicas de recolha de informação, proporcionando uma análise mais intensiva e uma melhor resposta aos objetivos de pesquisa.

Importa, ainda, referir que o presente estudo surgiu no âmbito da dissertação de mestrado em gerontologia social da Universidade Lusófona de Lisboa, decorrido no ano de 2019-2020, pelo que cumpriu e respeitou todos os procedimentos previstos no Centro Hospitalar Universitário de Lisboa Central, tendo sido sujeito a uma autorização própria para a sua concretização na instituição e de acordo com as normas éticas e deontológicas em vigor.

\section{Resultados}

No ano de 2018, verificou-se o registo total de 42 doentes em protelamento de alta por motivos sociais, contudo 36 eram idosos, ou seja, com idade igual ou superior a 65 anos. Assim, os idosos em protelamento de alta no SUP de São José caracterizaram-se por serem, maioritariamente, do género feminino, com idades entre os 81-85 anos, residentes em Lisboa, viúvos, com múltiplas patologias, não isentos de taxas moderadoras por insuficiência económica, tendo como principal motivo de admissão doença e uma média dependência após episódio de urgência. (Quadro nº1)

Quadro n¹. Perfil do utente
\begin{tabular}{|c|l|c|c|}
\hline \multicolumn{3}{|c|}{} & \\
\hline \multirow{3}{*}{ Género } & $\mathrm{F}$ & $\mathrm{N}$ & $\%$ \\
\cline { 2 - 4 } & $\mathrm{M}$ & 27 & $75 \%$ \\
\hline \multirow{5}{*}{ Idade } & $65-70$ & 9 & $25 \%$ \\
\cline { 2 - 5 } & $71-75$ & 3 & $8 \%$ \\
\cline { 2 - 5 } & $76-80$ & 5 & $14 \%$ \\
\cline { 2 - 5 } & $81-85$ & 8 & $22 \%$ \\
\hline
\end{tabular}




\begin{tabular}{|c|c|c|c|}
\hline & $86-90$ & 6 & $17 \%$ \\
\hline & 91-95 & 1 & $3 \%$ \\
\hline & 96-99 & 2 & $6 \%$ \\
\hline & $>100$ & 1 & $3 \%$ \\
\hline & Casado (a) / U. Facto & 6 & $17 \%$ \\
\hline & Viúvo (a) & 22 & $61 \%$ \\
\hline Estado Civil & Solteiro (a) & 6 & $17 \%$ \\
\hline & Divorciado (a) & 1 & $3 \%$ \\
\hline & sem dados & 1 & $3 \%$ \\
\hline & Sim & 13 & $36 \%$ \\
\hline Isençao IM & Não & 23 & $64 \%$ \\
\hline & Múltiplas patologias & 24 & $67 \%$ \\
\hline Patologias & Cardíaco & 1 & $3 \%$ \\
\hline & Neurológico & 1 & $3 \%$ \\
\hline & Ortopédicas & 10 & $28 \%$ \\
\hline
\end{tabular}

A análise dos motivos de protelamento foi efetuada tendo em conta duas determinantes: obstáculos à alta e situação familiar. Assim, no que se refere aos obstáculos à alta destacaram-se fundamentalmente dois: incapacidade/indisponibilidade de rede de suporte informal (14 doentes; 39\%) e a insuficiência/demora da resposta social formal ( 9 doentes; 25\%), e que representam o total de 23 doentes, ou seja $64 \%$ dos casos. (Gráfico $\left.n^{\circ} 1\right)$

\section{Gráfico n. ${ }^{\circ} 1$. Motivos de protelamento}
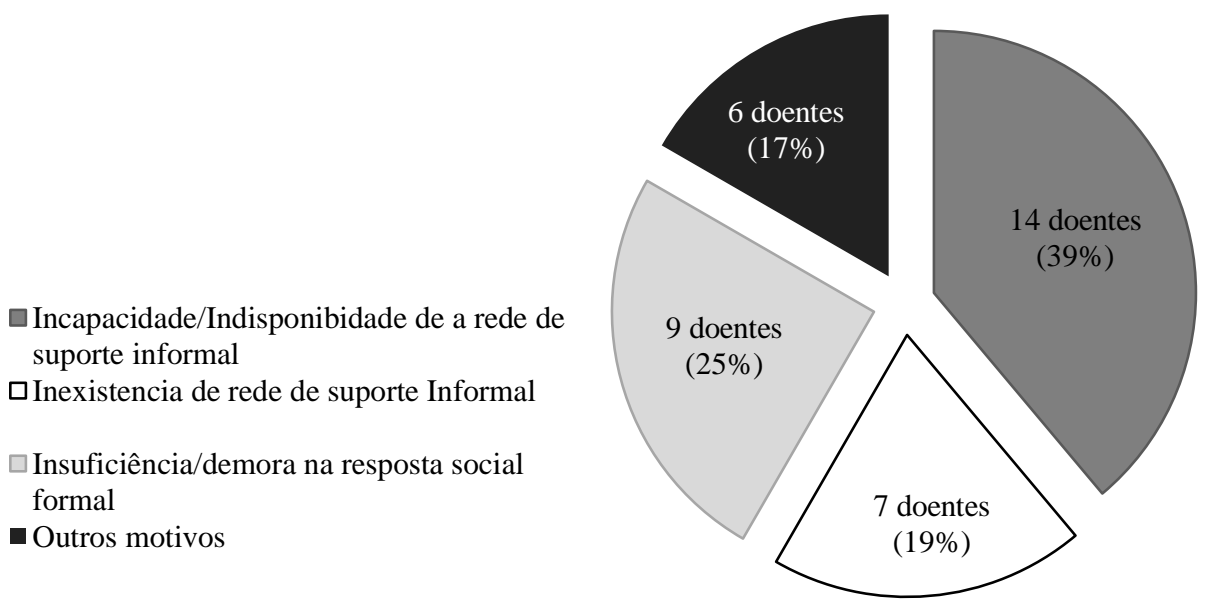

Quanto à situação familiar, a maioria dos utentes eram isolados ou cuja rede de suporte familiar não tinha disponibilidade para a prestação de apoio. Avaliado o grau de 
dependência e a situação familiar, verificou-se que é sobretudo nas situações de idosos totalmente dependentes que se registam as maiores taxas de recusa por parte da família para prestar apoio, bem como por indisponibilidade e incapacidade ou até por recusa expressa (e que representam 10 dos idosos). Esta recusa/ indisponibilidade baixa para oito casos, quando se trata de idosos com semi-dependência. Tais resultados permitem concluir que o estado de dependência do utente estará diretamente relacionado com os obstáculos à alta, sendo determinante a situação familiar/ redes de suporte existente previamente. (Quadro n⿳2)

\section{Quadro $n^{\circ} 2$. Situação familiar e grau de dependência}

\begin{tabular}{|l|c|c|c|c|c|c|}
\cline { 2 - 8 } \multicolumn{1}{c|}{} & \multicolumn{6}{c|}{ Grau de dependência } \\
\cline { 2 - 8 } \multicolumn{1}{c|}{} & Autónomo & \multicolumn{2}{c|}{$\begin{array}{c}\text { Semi- } \\
\text { dependente }\end{array}$} & \multicolumn{2}{c|}{$\begin{array}{c}\text { Totalmente } \\
\text { dependente }\end{array}$} \\
\hline Situação familiar & $\mathrm{N}$ & $\%$ & $\mathrm{~N}$ & $\%$ & $\mathrm{~N}$ & $\%$ \\
\hline C/suporte familiar & 0 & $0 \%$ & 4 & $11 \%$ & 1 & $3 \%$ \\
\hline Incapacidade de prestação de apoio & 0 & $0 \%$ & 4 & $11 \%$ & 1 & $3 \%$ \\
\hline Indisponibilidade de prestação de apoio & 0 & $0 \%$ & 3 & $8 \%$ & 5 & $14 \%$ \\
\hline $\begin{array}{l}\text { isolado/inexistência de rede de suporte } \\
\text { familiar }\end{array}$ & 0 & $0 \%$ & 8 & $22 \%$ & 5 & $14 \%$ \\
\hline Recusa em receber familiar & 0 & $0 \%$ & 1 & $3 \%$ & 4 & $11 \%$ \\
\hline
\end{tabular}

Quanto ao destino pós-alta verificou-se que a maioria dos utentes acabou por regressar ao domicílio (19 casos, ou seja 53\%) ou por ser encaminhado para resposta de Estrutura Residência para Idosos - vaga de emergência (15 casos, ou seja 41\%). (Gráfico $\left.\mathrm{n}^{\mathrm{o}} 2\right)$

No entanto, como referido acima, a análise do destino pós-alta e a definição da resposta social requerem a análise de outros fatores, como sejam a situação familiar e o nível de dependência do próprio idoso. 
- Domicilio

$\square$ Domicilio de familiar

口ERPI

a Internamento

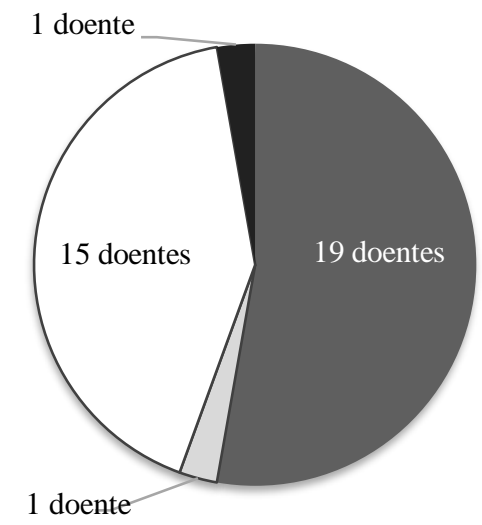

Assim, efetuada a análise do fator dependência e o destino pós-alta, verificou-se que os doentes que retornaram ao domicílio, tinham uma média dependência, sendo que a maioria estava isolado, pelo que nestas situações o apoio foi assumido através da rede formal. De seguida surgem os doentes com suporte familiar, que, na sua maioria, também retornaram ao domicílio, tendo sido acionada resposta formal de Serviço de Apoio Domiciliário (Santa Casa da Misericórdia de Lisboa /Instituições Particulares de Solidariedade Social/Instituições Particulares). Os utentes que ficaram com dependência total, tiveram como principal destino as Estruturas Residências para Idosos (ERPI), sendo que nestas situações, destacou-se a indisponibilidade da família para prestação de apoio e/ou dos doentes isolados. Verificou-se que para os doentes isolados, o fator da dependência, foi fundamental para a definição da resposta social, já para doentes com média dependência, a situação familiar foi influenciadora na definição da resposta. (Quadro n³)

Quadro n³. Destino Pós-alta e o grau de depência

\begin{tabular}{|l|c|c|c|c|c|c|c|c|}
\hline & \multicolumn{9}{|c|}{ Destino pós-alta } \\
\cline { 2 - 10 } & Domicílio & Domicílio de familiar & \multicolumn{2}{|c|}{ ERPI } & \multicolumn{2}{|c|}{ Internamento } \\
\hline Grau de dependência & $\mathrm{N}$ & $\%$ & $\mathrm{~N}$ & $\%$ & $\mathrm{~N}$ & $\%$ & $\mathrm{~N}$ & $\%$ \\
\hline Autónomo & 0 & $0 \%$ & 0 & $0 \%$ & 0 & 0 & 0 & 0 \\
\hline Semi-dependente & 14 & $39 \%$ & 1 & $3 \%$ & 5 & $14 \%$ & 0 & 0 \\
\hline Totalmente dependente & 5 & $14 \%$ & 0 & $0 \%$ & 10 & $28 \%$ & 1 & $3 \%$ \\
\hline & 19 & $53 \%$ & 1 & $3 \%$ & 15 & $42 \%$ & 1 & $3 \%$ \\
\hline
\end{tabular}

No que se refere aos dias de protelamento no SUP, verificou-se, em 2018, uma média de 3,02 dias de protelamento do doente idoso. Assim, dos 36 casos de protelamento, 24 utentes, ou seja $66 \%$ dos idosos ficaram dois ou mais dias e 12 utentes, ou seja $34 \%$, ficou um dia em protelamento de alta por motivos sociais. Os doentes que permaneceram um dia em protelamento, na sua maioria, tinham rede de suporte familiar, contrariamente, aos doentes que permaneceram dois ou mais dias, que eram isolados. $\mathrm{Na}$ 
maioria dos doentes que permaneceram dois ou mais dias, a rede de suporte informal manifestou incapacidade/indisponibilidade para prestação de apoio, mas também se verificou como obstáculos relevantes no maior número de dias, a demora na resposta por parte da rede formal. (Quadro $\mathrm{n}^{\circ} 4$ )

Quadro n. ${ }^{\circ}$. Número de dias de protelamento

\begin{tabular}{|r|c|c|c|c|c|}
\hline \multirow{2}{*}{} & \multicolumn{5}{|c|}{$N^{\text {o }}$ de dias de protelamento } \\
\cline { 2 - 7 } & $\begin{array}{c}1 \\
\text { Dia }\end{array}$ & $\begin{array}{c}2 \\
\text { dias }\end{array}$ & $\begin{array}{c}3 \\
\text { dias }\end{array}$ & $\begin{array}{c}4 \\
\text { dias }\end{array}$ & 5 ou + dias \\
\hline N & 12 & 7 & 3 & 6 & 8 \\
\hline Situação Familiar (N) & $19 \%$ & $8 \%$ & $17 \%$ & $22 \%$ \\
\hline c/suporte familiar & 4 & 0 & 0 & 0 & 1 \\
\hline Incapacidade de prestação de apoio & 2 & 1 & 1 & 0 & 1 \\
\hline Indisponibilidade de prestação de apoio & 3 & 1 & 1 & 1 & 2 \\
\hline Isolado & 3 & 3 & 0 & 3 & 4 \\
\hline Recusa em receber familiar & 0 & 2 & 1 & 2 & 0 \\
\hline Total & 12 & 7 & 3 & 6 & 8 \\
\hline
\end{tabular}

Salienta-se que o número de protelamentos do SUP do Hospital de São José, no ano de 2018, não foi significativo face ao número de doentes saídos. Apesar de não ter sido possível reunir informação específica dos doentes com idade igual ou superior a 65 anos que recorrem e têm alta do referido serviço, verificou-se que nesse ano, dos 150.301 doentes saídos (doentes admitidos e que tiveram alta do SUP com diferentes destinos), apenas 42 doentes (total de doentes protelados no SUP por motivos sociais) ficaram em protelamento de alta por motivos sociais, perfazendo cerca de $0,027 \%$ da população que recorre a este serviço.

Pese embora a pouca expressão destes dados, tal não significa que a permanência de um idoso num serviço com estas características não se revele problemática e potenciador das vulnerabilidades existentes, à partida, nesta população.

Das entrevistas realizadas à equipa multidisciplinar resultam claros os motivos para esta afirmação e que podem ser agrupados em três ordens de fatores: um primeiro associado à própria estrutura do serviço, que não possibilita a prestação de cuidados de qualidade para necessidades de longo prazo (dado que está destinado para a resposta 
imediata/urgente/emergente); um segundo fator associado ao funcionamento destes serviços, marcado por uma elevada rotatividade dos profissionais, doentes e familiares, o que leva a uma despersonalização e desumanização dos cuidados prestados, dificultando a capacidade de uma resposta de cuidado com dignidade, o que pode também levar ao agravamento do estado clinico do doente; um terceiro fator associado à sobrecarga dos recursos humanos e físicos/estruturais existentes no SUP, que deveriam estar canalizados para uma resposta aos doentes críticos/agudos.

Daí, muitas vezes, a solução ser o internamento ${ }^{5}$, o que levanta novos problemas, nomeadamente ao nível da gestão de vagas dos serviços de internamento, (que em períodos de maior afluência são escassas) e a ocupação de uma cama do internamento para um doente não agudo e sem necessidade de cuidados hospitalares.

Em todos estes momentos, o serviço social assume um papel fundamental, especificamente no SUP, com os entrevistados a destacarem a função do assistente social como elemento de mediação entre o utente, instituição, equipa médica, rede de suporte e comunidade.

O serviço social no âmbito do desenvolvimento do plano de alta executa diferentes acções durante o processo e acompanhamento de um caso. Estas ações enquadram-se nas competências e ações do serviço social, que visam mediar a situação de abandono familiar, concretizando princípios como: ampliação da liberdade, emancipação e pleno desenvolvimento dos indivíduos; defesa intransigente dos direitos humanos contra todo o tipo de arbítrio e autoritarismo; defesa da equidade e da justiça social, universalizando o acesso a bens e serviços relativos a programas e políticas sociais e a sua gestão democrática; compromisso com a qualidade na prestação de serviços, competência profissional e articulação com outros profissionais e trabalhadores (Silva, Marinho \& Delfino, 2016).

Assim, verificou-se que foi efetuado o acolhimento social a todos os utentes, ou seja, 36 doentes, sendo este o momento em que o assistente social prestou informações generalistas acerca dos direitos e deveres do utente, centralizando-se na recolha de elementos para a preparação da alta e continuidade de cuidados. Igualmente, relevante é a sua articulação com a rede de suporte informal, tendo sido esta efetivada em 22 doentes (61\%). De seguida, destacam-se os encaminhamentos e articulações efetuadas para as

\footnotetext{
${ }^{5}$ Segundo procedimento interno, o período máximo de permanência no SUP deverá ser 48h, devendo no caso de impossibilidade de alta social, optar pelo internamento por motivos sociais. Esta decisão é tomada conjuntamente pela equipa multidisciplinar, equipa de Serviço Social e Direção do SUP.
} 
respostas sociais: Ação Social (17 doentes), Serviço de Apoio Domiciliário (17 doentes), Estrutura Residencial para Idosos (5 doentes). Salienta-se, ainda, duas ações desenvolvidas pelo serviço social, no âmbito dos protelamentos de alta: a mediação de conflitos e a sinalização ao Ministério Público (Quadro nº5).

Quadro n. ${ }^{5}$. Síntese das ações desenvolvidas pelo Serviço Social no protelamento de alta

\begin{tabular}{|l|c|c|}
\hline Açães desenvolvidas & N & $\%$ \\
\hline Acolhimento social & 36 & $100 \%$ \\
\hline Articulação/Mediação com equipa multidisciplinar & 36 & $100 \%$ \\
\hline Articulação com rede informal & 22 & $61 \%$ \\
\hline Articulação/Encaminhamento para Ação Social Local - SCML/ ISS,IP & 17 & $47 \%$ \\
\hline Articulação/Encaminhamento para Serviço de Apoio Domiciliário & 17 & $47 \%$ \\
\hline Articulação/Encaminhamento para Estrutura Residencial para Idosos & 5 & $14 \%$ \\
\hline Elaboração de informação social & 16 & $44 \%$ \\
\hline Articulação/Encaminhamento Centro de Dia & 0 & $0 \%$ \\
\hline Articulação/Encaminhamento para Forças de Segurança Pública & 1 & $3 \%$ \\
\hline Sinalização ao Ministério Público & 3 & $8 \%$ \\
\hline Mediação de conflitos & 6 & $17 \%$ \\
\hline
\end{tabular}

Contudo, existem dificuldades e potencialidades na intervenção em equipa multidisciplinar em contexto de SUP, sendo estes, também, determinantes para o desenvolvimento do plano de intervenção pelo serviço social. Assim, as dificuldades que se destaca associa-se à rotatividade e número elevado de profissionais. Pois, num SUP existem múltiplas especialidades e profissionais de várias categorias, o que confere uma maior complexidade na intervenção, porque as perspetivas que cada profissional desenvolve sobre um doente são sempre diferentes. Todavia, estas também podem possibilitar o desenvolvimento de uma avaliação integrada e complementar a diferentes níveis, num único local e num curto espaço de tempo. Nestes momentos, o assistente social tem um papel fundamental na triagem, análise e avaliação das situações sinalizadas, enquanto desenvolve a integração destas perspetivas no plano de intervenção, em prol do doente, conciliando todas as demais dimensões.

\section{Conclusão}


Ao longo deste artigo procurou-se discutir a questão da gestão do protelamento de alta do doente idoso, no SUP, possibilitando conhecer o perfil do utente, os motivos de protelamento, destino pós-alta e os dias de protelamento, bem como o trabalho desenvolvido pela equipa multidisciplinar.

Apesar das dificuldades na identificação e caracterização do presente tema em contexto de SUP, existem características que são comuns a outros serviços hospitalares, assumindo-se o protelamento de alta hospitalar, numa fase inicial e de forma provisória, como uma resposta alternativa no sentido da manutenção das condições básicas de vida dos utentes. Porém, a permanência prolongada, embora continuem a ser asseguradas as condições básicas, começam a surgir outros problemas que podem ter implicações diretas nas condições de saúde, mas também na privacidade, conforto, autonomia e liberdade do utente. A escassez de recursos e respostas sociais, a indisponibilidade de apoio ou o tempo necessário para a reorganização familiar aliada à carência económica, constitui-se, como refere Jesus (2017), como os principais motivos do protelamento prolongado da alta hospitalar.

Sendo esta a realidade diária dos serviços de urgência em Portugal, a tomada de medidas imediatas que enquadrem a definição e criação de estratégias concertadas, revela-se emergente. Estratégias que poderiam, eventualmente, passar pela criação de protocolos com os serviços da comunidade para obtenção de uma resposta imediata a doentes vulneráveis, especificamente, idosos. Sabemos que medidas estratégicas de intervenção, como a realização de acolhimentos sistemáticos nos internamentos, são já tomadas, permitindo uma identificação e intervenção o mais precoce possível. Todavia, num SUP esta estratégia não é possível, pois o serviço social não tem capacidade para avaliar todos os doentes que são admitidos. Contudo, garantir a identificação de necessidades no SUP, mesmo quando o doente é internado e garantir eficazmente a identificação desses casos e a articulação imediata com as assistentes sociais dos serviços de internamento, poderia revelar-se uma oportunidade para o serviço social.

Para além dos diversos fatores que podem influenciar as determinantes dos protelamentos sociais, há ainda que ter em consideração fatores imprevistos e incontroláveis, como o atual contexto de pandemia mundial, com consequências diretas e indiretas na prestação e qualidade de serviços prestados aos doentes COVID-19 e principalmente aos doentes Não COVID-19. Neste contexto os próprios profissionais têm vindo a acompanhar a "metamorfose" desta pandemia, com as adaptações sucessivas de procedimentos. 
A admissão, avaliação e permanência de doentes vulneráveis, como os idosos, com múltiplas patologias, no SUP requer, atualmente, do serviço social que a avaliação dos fatores presentes na sua intervenção - como a identificação da rede de suporte informal/familiar e formal, respostas sociais e respetivo destino pós-alta - tenham de ser "pensados" de uma forma criteriosa, requerendo por parte dos profissionais a identificação e integração constante destes elementos na construção do plano de intervenção.

\section{Referências bibliográficas}

Associação Portuguesa de Administradores Hospitalares (2018). Barómetro de Internamentos Sociais.

Bardin, L. (1995). Análise de conteúdo. Lisboa, Portugal: Edições 70. Lusodidacta.

Bywaters, P. \& Mcleod, E. (2003). Social Care's impact in emergency medicine: a model to test. Emerg Med J., 20, 134-137. doi: 10.1136/emj.20.2.134

Cancela, D. (2007). Processo de Envelhecimento. Portal dos Psicológos.

Direcção-Geral de Saúde (2004). Circular informativa no 12/DSPCS.

Espírito Santo, I. (2018). O processo de acreditação hospitalar, desafios na prática profissional dos Assistentes Sociais. Viseu, Portugal: Edições Esgotadas.

Ferreira, F. \& Espírito Santo, I. (2018). Planeamento de alta hospitalar: perspetivas e reflexões acerca dos protelamentos sociais em Portugal. Alternativas. Cuadernos de Trabajo Social, 25, 33-50. doi: 10.14198/ALTERN2018.25.02

Ferreira, F. (2012). O Idoso Hospitalizado: responder às necessidades perspectivando a satisfação do utente. Dissertação de mestrado, Escola de Sociologia e Políticas Públicas do ISCTE - IUL, Portugal.

Ferreira, P. (2020). Envelhecimento populacional e mercado de trabalho: que lugar para os trabalhadores mais velhos? Revista Científica de Intervenção Social, Política e Desenvolvimento Comportamental, 1, 91-118.

Guerra, I. (2017). O caso social em saúde: uma dimensão do Serviço Social em contexto hospitalar. Public Sciences \& Policies, 1 (3), 57-79. doi: 10.33167/2184-0644. CPP2017.VIIIN1/pp.57-79

Imaginário, C. (2008). O Idoso Dependente, em contexto familiar (2 $2^{\mathrm{a}}$ ed.). Coimbra, Portugal: Formasau.

Jesus, A. (2017). Alta Hospitalar, Serviço Social e Direitos Humanos. Dissertação de mestrado, Escola de Sociologia e Políticas Públicas do ISCTE - IUL, Portugal.

Lopes, M., Ribeiro, A., Santo, I., Ferreira, F. \& Frederico, L. (2013). Serviço Social e Qualidade em Contexto Hospitalar. In Carvalho, M. et al. Serviço Social na Saúde. Lisboa, Portugal: Pactor.

Lessard-Hébert, M.; Goyette, G.; Boutin, G. (1990). Investigação Qualitativa: Fundamentos e Praticas. Lisboa, Portugal: Piaget. 
Ministério da Saúde (2010). Organização interna e a governação dos Hospitais, Grupo Técnico para a Reforma da Organização Interna dos Hospitais. Grupo Técnico para a Reforma da Organização Interna dos Hospitais.

Masfret, D.C. (2012). O Serviço Social de saúde e o planeamento da alta para a continuidade dos cuidados na comunidade. In Carvalho, M. et al. O Serviço Social na Saúde. Lisboa, Portugal: Pactor.

Oliveira, P., Frutoso, B., Verissimo, R \& Agripino, A. (2017) O Doente Idoso no Serviço de Urgência. Galicia clínica 78(1), 11-14. doi: 10.22546/43/1055

Pires, M.M. (2000). O Ponto de vista do Assistente Social. In AAVV (2000). Cuidados Paliativos. Coimbra, Portugal: Formasau.

Ramos, S. A. (2015). A influência do planeamento de alta hospitalar no número de dias de internamento do doente. Dissertação de mestrado em Gestão de Unidade de Saúde, ULHT.

Sequeira, C. (2010). Adaptação e Validação da Escala de Sobrecarga do Cuidador de Zarit. Revista Referencia. Mar, 12(2), 9-16.

Salvi, F., Morichi, V., Grilli A., Giorgi, R., Tommaso, G. \& Dessí- Fulgheri, P. (2007). The Elderly in the Emergency Department: A critical review of problems and solutions. Intern Emergency Medicine, 2(4), 292-301. doi: 10.1007/s11739-007-0081-3

Silva, A., Marinho, T. \& Delfino, M. (2016). Abandono familiar de paciente idosos: uma demanda para o assistente social no hospital de Urgência de Goiana. Revista Científica da Escola Estadual de Saúde Publica Cândido Santiago- RESAP, 2(1), 13-26.

Serafim, M. \& Santo, I. (2013). Criação e Validação de uma Escala de Complexidade da Intervenção Social com Adultos em Contexto Hospitalar. CIES eWorking Paper, 152/2013.

Vala, J. (2007). A análise de conteúdo. In Silva, S. A., Pinto, M. J. (Orgs.). Metodologia das Ciências Sociais (14 ${ }^{\mathrm{a}}$ Edição). Porto, Portugal: Edições Afrontamento.

Yin, R. K. (1994). Pesquisa Estudo de Caso - Desenho e Métodos (2a ed.). Porto Alegre, Brasil: Bookman. 